\title{
Predicting the energy budget of the scallop Argopecten purpuratus in an oxygen-limiting environment
}

\author{
Aguirre-Velarde Arturo 1, 2, ${ }^{*}$, Pecquerie Laure ${ }^{4}$, Jean Frederic ${ }^{2}$, Thouzeau Gerard ${ }^{3}$,
} Flye-Sainte-Marie Jonathan ${ }^{2}$

1 IMARPE, Lab Ecofisiol Acuat, Esquina Gamarra \& Gen Valle S-N Chucuito Callao, La Punta, Peru.

2 Univ Bretagne Occidentale, Ifremer, LEMAR, CNRS,IRD, Plouzane, France.

* Corresponding author : Arturo Aguirre-Velarde, email address : aaguirre@imarpe.gob.pe

\begin{abstract}
:
Low concentrations of oxygen determine marine species distribution and abundance along the Peruvian coast with consequences for human activity such as fishing and aquaculture. In order to assess bioenergetic consequences of oxygen limitation on the Peruvian scallop Argopecten purpuratus, we first developed a Dynamic Energy Budget (DEB) model of growth and reproduction calibrated on field experimental datasets. Then, we included oxygen availability as an additional forcing variable using a simple rule based on the ability of the scallop to regulate oxygen consumption. The resulting model was tested using growth/reproduction monitoring and simultaneous high frequency environmental records in Paracas Bay (Peru) at two different depths: suspended in the water column and on the sea bottom. Simulations indicated that scallops' growth and reproduction was not food-limited. The negative observed effects of hypoxia on growth and reproduction could be explained by a decrease in both assimilation and reserve mobilization. However, hypoxic conditions in summer were not sufficient to explain the observed losses in somatic tissue weights and the disruption of reproduction. The latter two patterns were better simulated when assuming increased somatic maintenance costs due to the presence of H2S during milky turquoise water discolouration events observed during summer.
\end{abstract}

\section{Highlights}

- High frequency recording in Paracas bay (Peru) showed frequent hypoxic conditions. Field observations showed decrease in growth and reproduction of Peruvian scallop. Oxygen availability was added to a DEB model developed for Peruvian scallop. Hypoxia is assumed to impact both assimilation and reserve mobilization.

Keywords : DEB theory, Bioenergetics, Hypoxia, Hydrogen sulfide, Growth, Reproduction, Peru 


\section{Introduction}

The abundant primary production in Peruvian coasts sustains a large biomass of primary and secondary consumers (e.g. small fish and bivalves). Nevertheless, as recently emphasized by Breitburg et al. (2018), these highly productive areas are the place of a paradox: they support some of the world's most prolific fisheries but are also associated with very strong oxygen-minimum zones (OMZ). Degradation processes of the large amount of settled organic matter consume the oxygen in deep waters and on the bottom (Gewin, 2010) generating a vast OMZ between 50 and $1000 \mathrm{~m}$ depth (Helly and Levin, 2004). Organic matter degradation in the absence of oxygen also produces toxic hydrogen sulfide $\left(\mathrm{H}_{2} \mathrm{~S}\right)$. Such giant $\mathrm{H}_{2} \mathrm{~S}$ plume has been reported off Peru (Schunck et al., 2013). However, OMZ impacts on littoral areas remains poorly known. High frequency environmental monitoring in Peruvian littoral bays recently revealed the frequent occurrence of strong oxygen limitations in very shallow areas (Aguirre-Velarde et al., 2016). These phenomena were also sporadically associated with the presence of milky, presumably sulfide-rich, waters. The impact of such events on resources and economic activities in these littoral bays (artisanal fisheries and aquaculture) is still poorly understood such and requires improving knowledge for an ecosystem-based sustainable management.

Unlike vagile organisms such as fishes that are, to some extent, able to avoid unfavorable conditions, sessile or semi-vagile organisms such as bivalves have to deal with local environmental constraints such as oxygen limitation. Although they have developed adaptations to cope with such events (AbeleOeschger and Oeschger, 1995; Diaz and Rosenberg, 1995; Levin, 2003), negative effects of hypoxia/anoxia on metabolism, physiology, growth, reproduction and survival have been described (Herreid, 1980; Grieshaber et al., 1994; Burnett and Stickle, 2001; Levin et al., 2009). A decrease of food consumption, increase in ventilation and heart beat rates, and the production of potentially toxic metabolites due to the activation of anaerobic pathways, may all affect the energetic budget of organisms subjected to oxygen-limiting conditions. The peruvian scallop is found on seabeds frequently affected by hypoxic/anoxic events and exhibits an important ability to cope with such events including to regulate its respiration and feeding rates (AguirreVelarde et al., 2016, 2018). Although low effects of daily cycles of hypoxia on A. purpuratus energy budget were found by Aguirre-Velarde et al. (2018), stronger effects of hypoxic/anoxic events, combined with the occurrence of milky waters were observed in the field (Paracas bay, Peru; Aguirre-Velarde, 2016).

Oxygen limitations naturally occur in Peru, but the frequency of hypoxic events globally tends to increase as a result of industrialization and climate change (Levin et al., 2009; Rabalais et al., 2010). Declining 
oxygen in global ocean and coastal waters is considered as one of the most important changes occurring in marine ecosystems (see review in Breitburg et al., 2018). This study aims to better understand and predict the effects of ocean deoxygenation on marine resources. The growth and reproduction responses of the Peruvian Scallop, A. purpuratus, under a highly variable environment, frequently limited in oxygen were modelled within the framework of Dynamic Energy Budget (DEB) theory (Kooijman, 2010). We first developed a standard DEB model for the benthic phase of $A$. purpuratus. We then added oxygen availability as a forcing variable of the model. The toxic effect due to the presence of milky waters was also taken into account by increasing somatic maintenance costs during these events. The resulting model was tested against high frequency observations of scallops exposed to hypoxic conditions in a culture area in Paracas Bay.

\section{Material and methods}

\subsection{Field data and observed patterns}

The dataset used in this study came from a survey undertaken in Paracas Bay $\left(13^{\circ} 49^{\prime} 35^{\prime \prime} \mathrm{S}, 76^{\circ} 17^{\prime} 43^{\prime \prime}\right.$ W), between August 28, 2012 and March 10, 2013 (late austral winter to summer) on a 5-m depth scallop aquaculture bed. Two size groups of scallops (group 1: $60-70 \mathrm{~mm}$, mean $=66.8 \pm \mathrm{CI} 0.97 \mathrm{~mm}$; group 2: $30-40 \mathrm{~mm}$, mean $=36.5 \pm$ CI $1.2 \mathrm{~mm}$ ) were exposed to two treatments. Half of both groups (780 ind.s each) was reared in the water column in suspended cages ( $2 \mathrm{~m}$ above the seabed) while the another half was reared in cages placed on the bottom (30 ind. per cage). Each group/treatment was sampled weekly by removal of one cage for measurement of shell height and dry weight (soma and gonads). Environmental conditions were simultaneously monitored at both depths using autonomous data-loggers. Temperature and oxygen saturation were recorded hourly whereas fluorescence of chlorophyll-a was recorded hourly for a $24 \mathrm{~h}$ period once a week. The occurrence of milky water events was visually monitored and recorded daily.

A small $\left(\approx 0.7^{\circ} \mathrm{C}\right)$ but significant difference was recorded between depths for the mean temperature (Wilcoxon test, $p<0.001$ ), it is small. Prolonged periods of severe hypoxia/anoxia were recorded during summer. Oxygen saturation was significantly lower near bottom than in the suspended treatment (Wilcoxon test, $p<0.001$ ), with median values of $25.6 \%$ and $39.4 \%$, respectively. Chlorophyll-a concentration (proxy of trophic resource) did not present a marked seasonality or significant differences between depths. Milky water events were recorded in 2013 on Jan. 03, Jan. 28, Feb. 07 and Mar. 04 and were accompanied by anoxic conditions (Fig. 1). 
Interestingly, although temperature and chlorophyll-a concentrations were close between culture conditions, important differences were observed for growth and gonadal investment (Fig. 5, data points) with higher growth in the suspended treatment compared to the bottom. In addition, in early summer (midDecember) when oxygen limitation was higher and when milky water events were more frequent, shell growth stopped in bottom-cultured scallops and was highly reduced in suspended-culture scallops after mid-January.

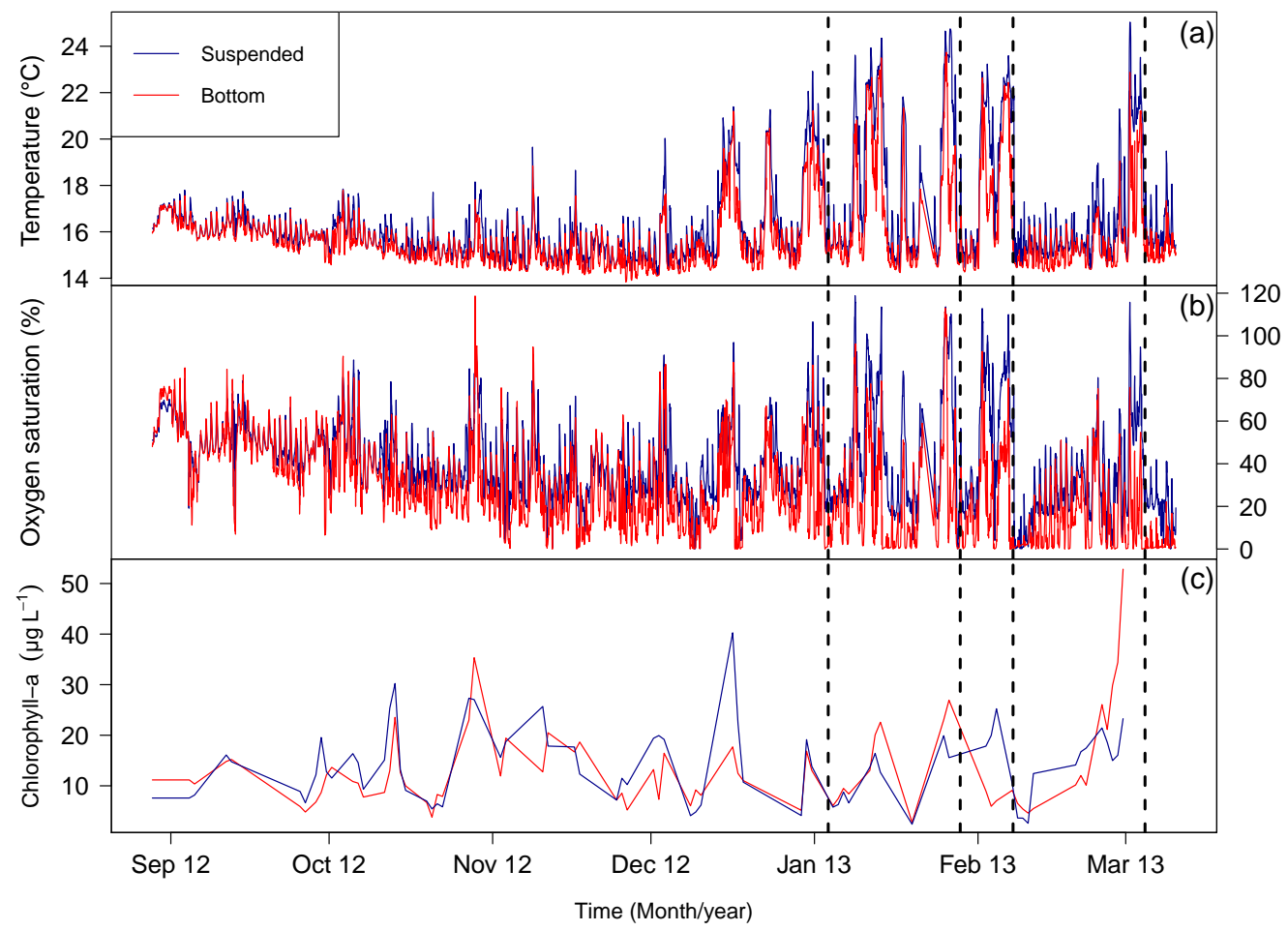

Figure 1: Environmental conditions monitored between August 2012 and March 2013 in Paracas Bay at 3 m depth (level of the suspended cages; blue lines) and on the bottom (red lines). (a): temperature, (b): oxygen saturation, (c): mean chlorophyll-a concentration estimated by fluorescence. The dotted vertical black lines indicate the occurrence of milky water discolouration events.

\subsection{Peruvian scallop bioenergetics}

\subsubsection{DEB model and additional assumptions}

A DEB model allows to quantify the energy acquisition and allocation within an individual through the dynamics of four state variables: structural volume $(V)$, reserve $(E)$ and reproduction buffer $\left(E_{R}\right)$ and maturity $\left(E_{H}\right)$. A conceptual scheme is given in Fig 2 . Briefly, the theory assumes that energy uptake from the 
environment is incorporated into a reserve pool. Energy mobilized from reserve is used for maintenance, growth, development and reproduction according to the so-called $\kappa$ rule: a fixed proportion $\kappa$ of the energy from reserve is allocated to maintenance and growth. The remaining fraction $1-\kappa$ is spent on development (increase in maturity, juvenile stage) and reproduction (adult stage). Maintenance processes have priority over growth, development and reproduction. Life stage transition occurs at the maturity thresholds $E_{H}^{b}$ (birth), $E_{H}^{j}$ (metamorphosis) and $E_{H}^{p}$ (puberty). A summary of the equations is given in Table 1. The uptake rate (i.e. assimilation rate; $\dot{p}_{A}$ ) is taken to be proportional to structural surface area of the organism. Dynamics of the reserve can be computed as the difference between assimilation $\left(\dot{p}_{A}\right)$ and energy mobilization $\left(\dot{p}_{C}\right)$. Structural maintenance rate $\left(\dot{p}_{M}\right)$ depends on structural volume in ectotherms. Maturity maintenance increases with maturity level (proportional to $E_{H}$ ) until puberty, i.e. once $E_{H}^{p}$ is reached. In adults, energy for reproduction is allocated to a reproduction buffer and emptied (at least partially) at each spawning event. All physiological rates are assumed to depend on temperature in the same way and to follow an Arrhenius relationship (see Table 1). Further details regarding DEB theory can be found in Kooijman (2010), Sousa et al. (2010) and Nisbet et al. (2012). As for many bivalve species, we considered a model with acceleration between birth and metamorphosis ("abj") to better represent the larval and adult phases.

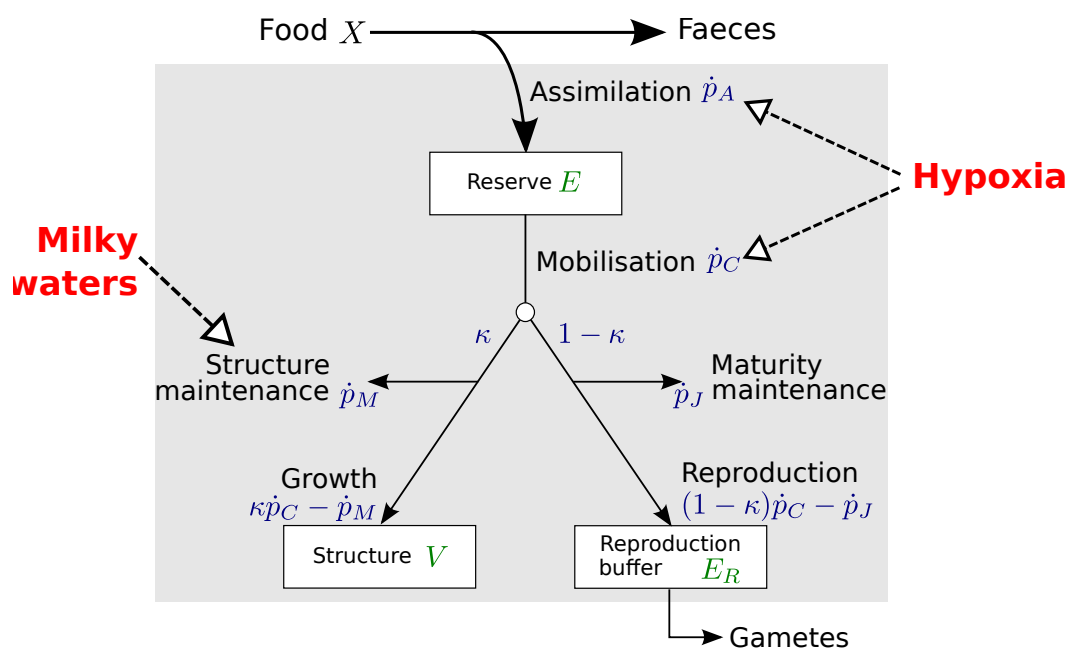

Figure 2: Conceptual scheme of the DEB model applied to the Peruvian scallop. Continuous arrows corresponds to the standard DEB model. The effects of hypoxia and toxicity related to the occurrence of milky turquoise waters are represented by dotted arrows.

When the mobilization rate is not sufficient to cover maintenance costs $\left(\kappa \dot{p}_{c}<\dot{p}_{M}\right.$ and/or $\left.(1-\kappa) \dot{p}_{c}<\dot{p}_{J}\right)$ maintenance costs are covered in priority from reproduction buffer and, if not sufficient, from structure. To avoid an additional parameter, we assumed that the efficiency of remobilization of reproduction buffer from 
Table 1: Summary of the equations of the standard Dynamic Energy Budget model used in this study. Parameters values, units and definitions are provided in Table 4.

\begin{tabular}{|c|c|}
\hline Equation & Definition \\
\hline$c(T)=\exp \left(\frac{T_{A}}{T_{1}}-\frac{T_{A}}{T}\right)$ & Temperature correction factor (Arrhenius equation) \\
\hline$f=\frac{X}{X+K}$ & Holling type II scaled functional response to food density \\
\hline$\dot{p}_{A}=\left\{\dot{p}_{A m}\right\} f V^{2 / 3} c(T)$ & Assimilation rate \\
\hline$\dot{p}_{C}=\frac{[E]}{\left[E_{G}\right]+\kappa[E]}\left(\left[E_{G}\right] \dot{v} V^{2 / 3}+\dot{p}_{M}\right) c(T)$ & Reserve mobilization rate \\
\hline$\dot{p}_{M}=\left[\dot{p}_{M}\right] V c(T)$ & Maintenance rate \\
\hline$\dot{p}_{J}=\dot{k}_{J} E_{H} c(T)$ & Maturity maintenance rate \\
\hline$\frac{d E}{d t}=\dot{p}_{A}-\dot{p}_{C}$ & Reserve dynamics \\
\hline$\frac{d V}{d t}=\frac{\kappa \dot{p}_{C}-\dot{p}_{M}}{\left[E_{G}\right]}$ & Structural growth \\
\hline$\frac{d E_{H}}{d t}=(1-\kappa) \dot{p}_{C}-\dot{p}_{J} \quad$ if $E_{H}<E_{H}^{p}$ & Maturity dynamics (equals 0 , in adults) \\
\hline$\frac{d E_{R}}{d t}=\left((1-\kappa) \dot{p}_{C}-\dot{p}_{J}\right) \kappa_{R} \quad$ if $E_{H} \geq E_{H}^{p}$ & Reproduction buffer dynamics (equals 0 in juveniles) \\
\hline
\end{tabular}

structure equals $\kappa_{R}$.

Histological studies showed that the Peruvian scallop exhibits an important gametogenetic activity and is a "partial spawner", only releasing ripe gametes (Brown and Guerra, 1980; Avendaño and Le Pennec, 1996). In Paracas Bay, the reproductive activity occurs throughout the year (Wolff, 1988) with partial spawnings each $\approx 28$ days (gametogenesis-spawning) synchronised with the lunar cycle (Cueto-Vega, 2016). Monitoring of gonodo-somatic index indicated that $40 \%$ of the gonad weight is released at each spawning event (Cueto-Vega, 2016). Thus we introduced the following simple rules for handling the reproduction buffer: (1) spawning events were simulated every 28 days after the 5th of August to synchronise with the observed spawning cycles and (2) at each spawning event, $40 \%$ of the gonad content (taken as $E_{R}$ ) was 
released.

Table 2: Equations allowing to compute the observables from the standard DEB model state variables and energy fluxes. Parameter values, units and definitions are given in Table 4. ${ }^{a}: \dot{p}_{G}=\kappa \dot{p}_{C}-\dot{p}_{M}$ stands for the growth flux, $\dot{p}_{D}$ the dissipation flux that corresponds to the sum of $\dot{p}_{M}, \dot{p}_{J}$ and $(1-\kappa) \dot{p}_{C}-\dot{p}_{J}$ in juveniles, $\eta_{O *}$ are the coefficients that couple oxygen fluxes to energy fluxes $\left(\dot{p}_{*}\right)$. See supplementary material 1 of Thomas et al. (2018, this issue) for a detailed description of the computation of respiration rate and associated parameters definitions and units.

\begin{tabular}{|c|c|c|}
\hline Equations & Units & Definition \\
\hline$L_{w}=\frac{V^{(1 / 3)}}{\delta_{\mathcal{M}}}$ & $\mathrm{cm}$ & Shell height \\
\hline$W_{d}=d_{V d} V+\frac{E}{\rho_{E}}$ & $\mathrm{~g}_{d w}$ & Somatic dry weight \\
\hline$W_{w}=\frac{W_{d}}{w}$ & $\mathrm{~g}_{w w}$ & Somatic wet weight \\
\hline$W_{R w}=\frac{E_{R}}{\rho_{E} w}$ & $\mathrm{~g}_{w w}$ & Gonad wet weight \\
\hline$W_{d 0}=\frac{E_{0}}{\rho_{E}}$ & $\mathrm{~g}_{d w}$ & Egg dry weight \\
\hline$N=\frac{0.6 * E_{R}}{E_{0}}$ & \# & Fecundity $(60 \%$ gonad $=$ female $)$ \\
\hline$\frac{\dot{J}_{O}}{W_{d}}=\frac{\eta_{O A} \dot{p}_{A}+\eta_{O D} \dot{p}_{D}+\eta_{O G} \dot{p}_{G}}{W_{d}}$ & $\mathrm{~mol} \mathrm{O}_{2} \mathrm{~g}^{-1} \mathrm{~d}^{-1}$ & Dry weight-specific respiration rate ${ }^{a}$ \\
\hline
\end{tabular}

\subsubsection{Impacts of environmental stressors}

As reviewed by Thomas et al. (2018, this issue), the feeding process is commonly impaired by oxygen limitation ( $\mathrm{Wu}, 2002$ ), probably due to the high oxygen demand of digestive/assimilation processes (see Kramer, 1987; Willows, 1992). We thus assumed that the assimilation rate $\left(\dot{p}_{A}\right)$ was affected by low oxygen saturations according to Aguirre-Velarde et al. (2018). Under hypoxic conditions, energy production through aerobic metabolic pathways is impaired and less efficient anaerobic pathways are activated. As hypothesized in Aguirre-Velarde et al. (2018), we assumed that an organism under hypoxic conditions is limited in its ability to "mobilize" energy required for metabolic activities (maintenance, growth, and reproduction). This effect was accounted by modifying $\dot{p}_{C}$ as a function of oxygen saturation. For parsimony purpose, the same oxygen correction function $C_{D O}$ was applied on the assimilation rate $\dot{p}_{A}$ and the reserve mobilization rate $\dot{p}_{C}$ (Fig. 2; Eq. 2). Facing hypoxia, many organisms follow a so-called oxyregulator type 
law (e.g. see Herreid, 1980) as illustrated in Fig. 3. They exhibit a two-phase response: 1) Respiration rate is maintained above a critical saturation point $\left(S_{\mathrm{O}_{2} \mathrm{c}}\right.$, in \%), this phase is called oxyregulation, 2) Below this point, they are not able anymore to maintain their oxygen consumption, which decreases linearly with the oxygen saturation of the surrounding water $S_{O_{2}}$; this phase being called oxyconformity. A. purpuratus has been shown to exhibit such a two-phase response to hypoxia (Aguirre-Velarde et al., 2016). Accordingly, $C_{D O}$ was modelled as single parameter two-phase linear response (eq. 3 and illustrated in Fig 3 ).

$$
\begin{aligned}
\dot{p}_{A} & =c(T) C_{D O}\left\{\dot{p}_{A m}\right\} f V^{2 / 3} \\
\dot{p}_{C} & =c(T) C_{D O}\left(\frac{[E]}{\left[E_{G}\right]+\kappa[E]} \dot{v}\left[E_{G}\right] V^{2 / 3}+\dot{p}_{M}\right) \\
\text { with } C_{D O} & =\frac{S_{O_{2}}}{S_{O_{2} c}} \text { if } S_{O_{2}}<S_{O_{2} c} \\
& =1 \text { otherwise }
\end{aligned}
$$

where $C_{D O}$ varies between 1 and 0 . Under hypoxic conditions, below the organism regulatory capacities (i.e $S_{O_{2} c}$ ), the simultaneous decrease in the assimilation and mobilization fluxes restrict both reserve inputs and outputs proportionally to $C_{D O}$.

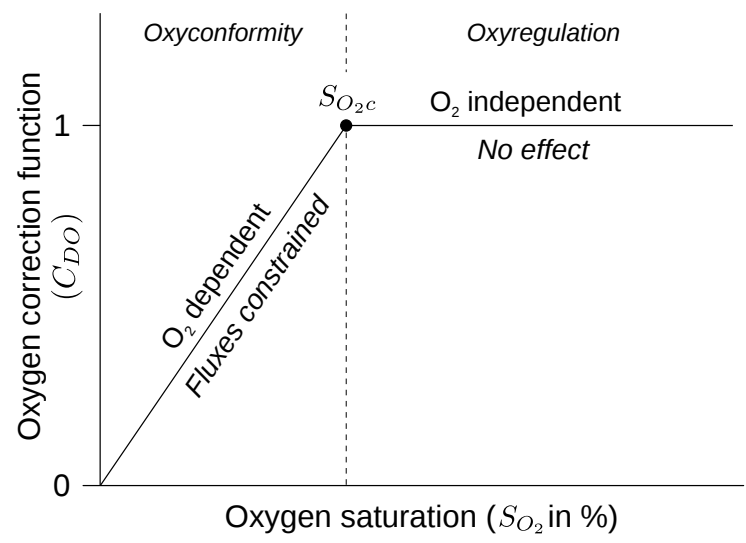

Figure 3: Illustration of the one parameter two-phase oxygen correction function used, based on the oxyregulator type law (Herreid, 1980): above $S_{O_{2} c}$ fluxes are maintained (oxyregulation) but they decrease linearly with oxygen saturation below $S_{O_{2} c}$ (oxyconformity). by high concentrations of toxic $\mathrm{H}_{2} \mathrm{~S}$ (Cabello et al., 2002; González-Hunt, 2010). In bivalves, exposition to sulfides may result in oxidative damage (Joyner-Matos et al., 2010) and production of oxydative stress proteins (Joyner-Matos et al., 2006) suggesting energy investment in cell repair. For simplicity sake, the 
Table 3: Comparison between "zero-variate" observed data used to estimate model parameters and values predicted by the DEB model. References of observed data and relative errors, calculated as $\frac{\text { predicted-observed }}{\text { observed }}$, are specified.

\begin{tabular}{|c|c|c|c|c|c|}
\hline Observable & Unit & $\begin{array}{c}\text { Observed } \\
\text { value }\end{array}$ & $\begin{array}{c}\text { Predicted } \\
\text { value }\end{array}$ & $\begin{array}{c}\text { Relative } \\
\text { error }\end{array}$ & Reference \\
\hline Egg dry weight $\left(W_{d 0}\right)$ & $\mathrm{g}$ & $3.182 \mathrm{e}-08$ & $3.102 \mathrm{e}-08$ & 0.0251 & Egg diameter $(=0.0066 \mathrm{~cm})$ (pers. obs.) \\
\hline Age at birth $\left(a_{b}\right)$ at $18^{\circ} \mathrm{C}$ & $\mathrm{d}$ & 4 & 0.4 & 0.900 & Bellolio et al. (1994) \\
\hline Age at puberty $\left(a_{p}\right)$ at $16^{\circ} \mathrm{C}$ & d & 100 & 61.3 & 0.386 & Estim. from Mendo et al. (1989) \\
\hline Life span & $\mathrm{d}$ & 1825 & 1802 & 0.013 & Stotz and Gonzalez (1997) \\
\hline Shell height at birth & $\mathrm{cm}$ & 0.01 & 0.015 & 0.538 & Bellolio et al. (1994) \\
\hline Shell height at puberty & $\mathrm{cm}$ & 3 & 3.3 & 0.100 & Mendo et al. (1989) \\
\hline Ultimate shell height & $\mathrm{cm}$ & 11 & 12.69 & 0.153 & Wolff (1987) \\
\hline Respiration rate* at $16^{\circ} \mathrm{C}$ & $\mathrm{mgO}_{2} \mathrm{~h}^{-1} \mathrm{~g}^{-1}$ & 0.66 & 1.2 & 0.818 & Aguirre-Velarde et al. (2016) \\
\hline Respiration rate* at $25^{\circ} \mathrm{C}$ & $\mathrm{mgO}_{2} \mathrm{~h}^{-1} \mathrm{~g}^{-1}$ & 1.13 & 1.98 & 0.752 & Aguirre-Velarde et al. (2016) \\
\hline Length as a function of time & $\mathrm{d}-\mathrm{cm}$ & figure not shown & & 0.02635 & Aguirre-Velarde et al. (2016) \\
\hline Somatic wet weight as a function of time & $d-g$ & figure not shown & & 0.08987 & Aguirre-Velarde et al. (2016) \\
\hline Gonad wet weight as a function of time & $d-g$ & figure not shown & & 0.3913 & Aguirre-Velarde et al. (2016) \\
\hline Fecundity as a function of length & $\mathrm{cm}-\#$ & figure not shown & & 0.3466 & Aguirre-Velarde et al. (2016) \\
\hline
\end{tabular}

* Normoxic conditions, for 3 -cm shell height individuals

effect of the occurrence of milky waters was modeled by multiplying maintenance costs $\left(\dot{p}_{M}\right)$ by a constant factor for three consecutive days (average observed duration of these events). Following Muller et al. (2010), we assumed that the damages induced by $\mathrm{H}_{2} \mathrm{~S}$ increased maintenance costs. During the simulation process, this factor was gradually increased to fit the model to growth/reproduction observations.

\subsection{Parameter estimation and model simulations}

The parameters of the standard DEB model for A. purpuratus were estimated following the AmP procedure (Marques et al., 2018, Matlab routines available at https://github.com/add-my-pet). We used both "zero-variate" data (set of single-valued trait observations) and "uni-variate data" (a dependent variable as a function of an independent variable). Zero-variate data are shown in Table 3. Uni-variate data came from growth and reproduction observations from group 2 suspended scallops and environmental monitoring performed in Paracas Bay during the late winter to spring 2012, a period during which hypoxia events have low incidence. 
Temperature, chlorophyll- $a$ and oxygen saturation time series obtained during the monitoring in Paracas Bay (Fig. 1) were linearly interpolated when needed to complete hourly data and used as forcing variables for simulations. Rules for the conversions of model theoretical variables into observable variables are given in Table 2.

\section{Results}

\subsection{Parameter estimation}

The DEB parameter set obtained for A. purpuratus is shown in Table 4. Zero-variate data, including both life history traits and physiological rates were predicted (Tab. 3) with mean relative error of 0.148 . However, age at puberty was underestimated by $38 \%$ and the maximum reproduction rate was $63 \%$ lower than the observed value. When including hypoxia and milky waters stress, the best match between simulations and observations was obtained for $S_{O_{2} c}$ value of $40 \%$ combined with an increase of $\dot{p}_{M}$ by a factor 6 when milky waters occur.

\subsection{Simulations}

The estimated half-saturation constant $(K)$ resulted in a simulated scaled functional response $(f)$ that remained close to 1 in both conditions (average $f=0.954$ on the bottom and 0.956 in the suspended treatment) thus suggesting low food limitation in scallops' growth and reproduction.

The obtained $C_{D O}$ times series (Fig. 4) are in average significantly lower on the bottom than in suspended culture $(p<0.01)$. At both depths, relatively low $C_{D O}$ values $(<0.5)$ occurred between November and March, with a particularly critical period between January and March during which values were close or equal to zero repeatedly, particularly at bottom. Note also that during the first half of February, considerably low $C_{D O}$ values were obtained for consecutive days both at bottom and in suspended culture.

Model simulations including the effect of hypoxia and milky waters (fig. 5) accurately predicted the difference observed in growth and reproduction between culture conditions (Fig. $5 \mathrm{a}$ and c). The model also predicted higher gonad growth and spawning amplitude in suspended treatment rather than at bottom, as observed (Fig. 5 d). The simple formulation for handling reproduction buffer, based on a 28-day spawning cycle, accurately simulated the periodic sharp decreases of gonadal weight (due to spawning events) before the beginning of environmental summer disturbances. As a consequence, simulated total wet weight was close to the observations under both experimental treatments (Fig. 5 d). Model simulations better fitted data for scallops of size group 2 (small initial size) than for those of size group 1 for which the model 
Table 4: List of estimated values, symbols, and units of the parameters for the standard A. purpuratus DEB model. All rates are expressed for a reference temperature of $T_{1}=293.15 \mathrm{~K}\left(20^{\circ} \mathrm{C}\right)$ and a functional response $f=1$. The values in parenthesis correspond to parameter values after acceleration in an "abj" model.

\begin{tabular}{|c|c|c|c|}
\hline Parameter & Symbol & Value & Units \\
\hline \multicolumn{4}{|l|}{ Primary parameters: } \\
\hline Digestion efficiency & $\kappa_{X}$ & 0.8 & - \\
\hline Maximum surface-area-specific assimilation rate & $\left\{\dot{p}_{A m}\right\}$ & $95.01(482.82)$ & $\mathrm{J} \mathrm{cm}^{-2} \mathrm{~d}^{-1}$ \\
\hline Volume-specific somatic maintenance rate & {$\left[\dot{p}_{M}\right]$} & 73.98 & $\mathrm{~J} \mathrm{~cm}^{-3} \mathrm{~d}^{-1}$ \\
\hline Volume-specific cost for structure & {$\left[E_{G}\right]$} & 2401 & $\mathrm{~J} \mathrm{~cm}^{-3}$ \\
\hline Energy conductance & $\dot{v}$ & $0.056(0.284)$ & $\mathrm{cm} \mathrm{d}^{-1}$ \\
\hline Fraction of utilized reserve for growth + som. maintenance & $\kappa$ & 0.6414 & - \\
\hline Maturity maintenance rate coefficient & $\dot{k}_{J}$ & 0.002 & $d^{-1}$ \\
\hline Maturity threshold at birth & $E_{H}^{b}$ & 0.000176 & $\mathrm{~J}$ \\
\hline Maturity threshold at metamorphosis & $E_{H}^{j}$ & 0.02324 & $\mathrm{~J}$ \\
\hline Maturity threshold at puberty & $E_{H}^{p}$ & 2525 & $\mathrm{~J}$ \\
\hline Fraction of the reproduction buffer fixed into eggs & $\kappa_{R}$ & 0.95 & - \\
\hline \multicolumn{4}{|l|}{ Auxiliary and compound parameters: } \\
\hline Arrhenius temperature & $T_{A}$ & 4746 & $\mathrm{~K}$ \\
\hline Shape coefficient & $\delta_{\mathcal{M}}$ & 0.33 & - \\
\hline Dry to wet weight ratio & $w$ & 0.09 & - \\
\hline Structure density (dry weight) & $d_{V d}$ & 0.09 & $\mathrm{~g}_{w w} \mathrm{~cm}^{-3}$ \\
\hline Energy density of reserve & $\rho_{E}$ & 23013 & $\mathrm{Jg}_{d w}^{-1}$ \\
\hline Half-saturation coefficient of scaled functional response & $K$ & 0.5 & $\mu \mathrm{g}_{\text {Chla }} \mathrm{L}^{-1}$ \\
\hline Maximum reserve density & {$\left[E_{m}\right]$} & $\frac{\dot{p}_{A m}}{\dot{v}}$ & $\mathrm{~J} \mathrm{~cm}^{-3}$ \\
\hline Scaled reserve density & $e$ & $\frac{[E]}{\left[E_{m}\right]}$ & - \\
\hline
\end{tabular}




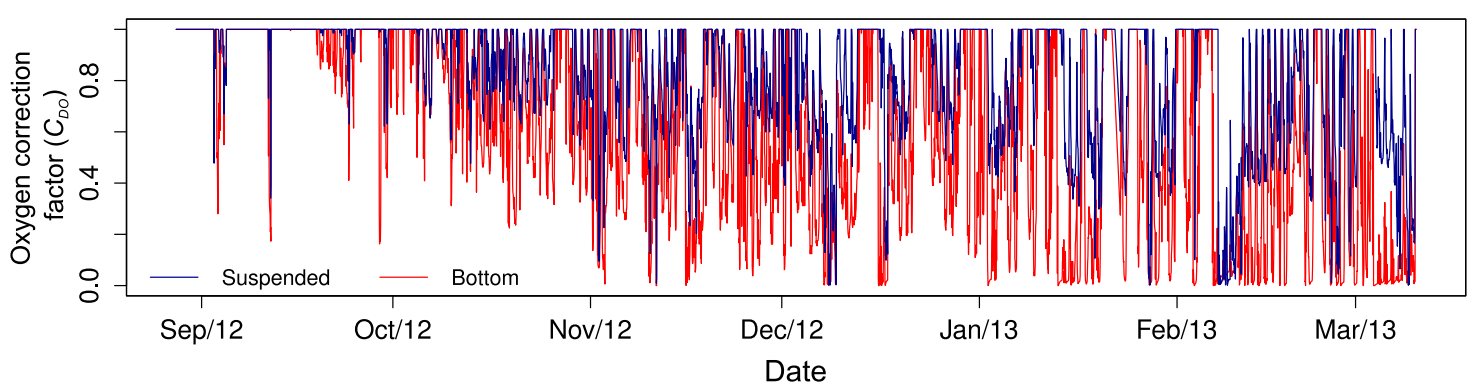

Figure 4: Temporal evolution of the oxygen correction function $C_{D O}$ obtained from environmental monitoring in Paracas bay (Fig. 1b) and taking into account $S_{O_{2} c}$ of $40 \%$. Both time series were used for the four model simulations presented in Fig. 5 (two depths and two different initial sizes).

(Fig. 5 c). At the same period, the model also predicted the decline observed sharp in the reproductive activity.

\section{Discussion}

\subsection{Estimation of model parameters for A. purpuratus}

The overall fit between data and predictions for the calibration procedure is good (Mean relative error MRE $=0.4$ ) given the number of data sets we used. The adjustment for the larval phase in particular needs improvement, but our objectives was to focus on the effect of hypoxia during the juvenile and adult stages and the fit for these stages is well satisfying. Predicted age at puberty (55.8 d) was lower than observed (100 d). It is possible that our value (age for $3-\mathrm{cm}$ shell height, pers. obs.) is slightly overestimated since first maturity for the Peruvian scallop has been reported at smaller sizes (1.3 and $2.5 \mathrm{~cm}$, Disalvo et al., 1984; Mendo et al., 1989, respectively). In addition, theses observations are based on the presence of a differentiated gonad, that occurs after onset of puberty (i.e. first allocation of energy to reproduction; Kooijman, 2010). This underestimation might also be linked to the fact that only life history traits data of the benthic phase of $A$. purpuratus were used for parameters estimations; including larval trait data might improve this pattern.

The Peruvian scallop is a simultaneous hermaphroditic species, producing both sperm and oocytes. Information about sperm production is rather scarce because it is less limiting in hatchery processes. For this reason, model parametrization only took into account the female gonad. A more precise estimate of reproduction rate must include the production of both oocytes and sperm. A. purpuratus has high growth and reproduction rates, captured in the model through the combination of high somatic maintenance costs 
( $\left[\dot{p}_{M}\right]=73.98$ compared to a typical value of $20 \mathrm{~J} \mathrm{~cm}^{-3} \mathrm{~d}^{-3}$; Kooijman, 2013) and low investment in structural growth and maintenance ( $\kappa=0.64$ compared to a typical value of 0.8 , Kooijman, 2013). This pattern, allowing fast growth and high reproduction rate, is consistent with Kooijman (2013) "waste to hurry" hypothesis. Lavaud et al. (2014) published a DEB parameter set for Pecten maximus, a Pectinidae with similar maximum length but slower growth. Comparatively, the estimated values of shape coefficient are similar for both species, but the $\kappa$ value for A. purpuratus was lower while values for structural maintenance costs $\left(\left[\dot{p}_{M}\right]\right)$ and energy conductance $(\dot{v})$ were higher. This combination of parameters reflects the highly energetic investment in reproduction and faster growth rate of $A$. purpuratus compared to $P$. maximus.

\subsection{Effects of Hypoxia}

DEB models can be useful to explore the consequences of environmental stress factors in order to better understand the ecological challenges that organisms are facing in the their natural environment. The present work combined with Lavaud et al. (2018, this issue) are the first DEB applications taking into account the impact of oxygen limitation. Chlorophyll- $a$ and temperature, were very similar between the two culture depths (suspended and bottom) and predicted growth and reproduction without the effect of hypoxia were thus very close between culture conditions. In both conditions food was rarely limiting. We introduced a simple rule for the effect of oxygen, based on the notion of critical oxygen saturation threshold $\left(S_{0_{2} c}\right)$ below which metabolism is dependent on oxygen saturation (see e.g. Herreid, 1980). This single parameter yet could capture the observed trends in growth and reproduction between culture depths. On the seabed, where exposure to hypoxia was frequent and sometimes prolonged, scallop growth and reproduction was highly impacted. Decreasing assimilation and mobilization fluxes below $S_{O_{2} c}$ restricted both the energy input and output from reserve towards metabolic functions (maintenance, growth, reproduction). It thus seems appropriate to use a single law, based on the ability of the organisms to regulate their oxygen consumption, to constrain both reserve mobilization and assimilation fluxes.

A $S_{O_{2} c}$ value of $40 \%$ was used for simulations but Aguirre-Velarde et al. (2016) rather found a $S_{O_{2} c}$ of $24 \%$ for juveniles. If hypoxia tolerance has been shown to depend on size, whether tolerance increases or decreases with size would to depend on species (e.g. see Dupont-Prinet et al., 2013a,b). In bivalves, there is evidence that tolerance to hypoxia decreases with size (Wang and Widdows, 1993; Hicks and McMahon, 2005). Recent experiments showed that bigger scallops survived hypoxia (1\% saturation) for less time than smaller ones (Cueto-Vega, R., unpublished data), thus indicating size-dependence of the tolerance to hypoxia in A. purpuratus. A higher $S_{O_{2} c}$ for bigger individuals is thus expected and is consistent with the idea 
that the ability to extract oxygen from the water depends on surface-to-volume ratio. Further experiments are needed to confirm this pattern. In addition, in natural environments, hypoxia is accompanied by other potential environmental stressors (e.g. $\mathrm{pH}, \mathrm{H}_{2} \mathrm{~S}$, high $\mathrm{POM}$ concentrations, etc.) that might interact with the $S_{O_{2} c}$ value. Further modeling approach in the DEB context could explore the effects of environmental stressors on the elemental balance level. This will require evaluating the relevance in terms of complexitybenefit. Various adaptations (biochemical, physiological, behavioural, etc.) would have to be considered wile the selected approach must by sufficiently flexible.

\subsection{Effect of milky waters}

Milky turquoise waters events in Paracas Bay have been associated with the presence of hydrogen sulphide $\mathrm{H}_{2} \mathrm{~S}$ (Schunck et al., 2013). The metabolic consequences of $\mathrm{H}_{2} \mathrm{~S}$ and/or elemental sulfur on filter feeders physiology remain poorly studied (see example in Laudien et al., 2002). In the present study, maintenance costs were increased by a factor of six during a fixed period of time ( 3 days, average duration of milky water events) to mimic its toxic effect. Under these conditions, when reserve mobilization is close to zero (anoxia or severe hypoxia), increased maintenance needs must be paid from the structure and reproduction buffer. The estimated multiplication factor is rather high but the modified $\left[\dot{p}_{M}\right]$ value stays within the range reported by Kooijman (2013) for unstressed organisms. The exposure time to milky waters was relatively short and it is likely that toxic effects of $\mathrm{H}_{2} \mathrm{~S}$ damage cells/tissues and the reparation of these lesions lasts longer than 3 days. Further experiments are needed to validate the hypothesis that $\mathrm{H}_{2} \mathrm{~S}$ strongly increases the maintenance costs and to improve the formulation and the calibration of the effect of $\mathrm{H}_{2} \mathrm{~S}$ in interaction with hypoxia/anoxia.

\subsection{Model limitations}

The Peruvian scallop is naturally exposed to large fluctuations of dissolved oxygen and must present metabolic, physiological and behavioural adaptations to hypoxia. While trends in growth and reproduction are well represented by the model, the underestimation of growth predictions for suspended scallops may show limitations of the model with a simple rule to capture the whole evolutionary adaptations of this species to deal with oxygen limitation. On the other hand, bottom scallops could potentially be exposed to other environmental stressors such as increased $\mathrm{CO}_{2}$ (decrease in $\mathrm{pH}$ ) due to respiration. It should not be ruled out either a greater exposure of bottom-growing scallops to $\mathrm{H}_{2} \mathrm{~S}$ diffusing from the sediment. The cumulative impacts of multiple stressors would often be worse than expected for a single stressor (Crain 
et al., 2008) which could explain the observed-predicted divergences, specially for scallops growing on bottom. As emphasized by Montalto et al. (2014), increasing the efforts to better characterize stressors in coastal areas at a relevant temporal resolution is necessary to improve the predictions.

The rule used for the restriction of metabolic fluxes allowed evaluating the global energetic consequences on the organism, but not the contribution of anaerobic metabolism below the regulation capacity. More or less efficient anaerobic metabolic pathways could have an impact on the organism's ability to cope with oxygen limitation (Hochachka and Buck, 1996), while the metabolism of anaerobic endproducts accumulated during hypoxia events could change the maintenance costs (e.g. oxygen debt), thus affecting the energy budget.

Primary production in the Peruvian coastal zone, though presenting a seasonality due to upwelling variability, is important throughout the year and is dominated by diatoms mainly (Rojas de Mendiola, 1981; Bruland et al., 2005). Under these conditions, the in situ chlorophyll- $a$ monitoring carried out represents well this abundant availability at both water depths (near to bottom and $2 \mathrm{~m}$ above the seabed). However, in other scenarios (comparison between different bays, latitudes, etc.) where the trophic resource is potentially different (e.g. in composition and/or quality), it is pertinent to include forcing variables that improve the characterization of the available food sources ( e.g. Thomas et al., 2011).

\section{Acknowledgements}

This work is part of a $\mathrm{PhD}$ thesis supported by IRD, within the framework of the LMI DISCOH, and LabexMER (ANR-10-LABX-19-01) and the PICS BISCOT. Additional funding was provided by the International Foundation of Science (IFS, grant number A/5210-1). We would like to acknowledge the participants of the summer school MEMS (Combining Modelling and Experimental approaches for Marine organisms under Stress, Brest, Aug. 29- Sept 2, 2016) for fruitful discussions.

\section{References}

Abele-Oeschger, D., Oeschger, R., 1995. Hypoxia-induced autoxidation of haemoglobin in the benthic invertebrates Arenicola marina (Polychaeta) and Astarte borealis (Bivalvia) and the possible effects of sulphide. J. Exp. Mar. Bio. Ecol. 187 (1), $63-80$. Aguirre-Velarde, A., 2016. La bioénergétique du pétoncle péruvien (Argopecten purpuratus) dans un contexte environnemental limitant en oxygène. Ph.D. thesis, École doctorale des Sciences de la Mer, Université de Bretagne Occidentale.

Aguirre-Velarde, A., Jean, F., Thouzeau, G., Flye-Sainte-Marie, J., 2016. Effects of progressive hypoxia on oxygen uptake in juveniles of the Peruvian scallop, Argopecten purpuratus (Lamarck, 1819). Aquaculture 451, 385-389. 
Aguirre-Velarde, A., Jean, F., Thouzeau, G., Flye-Sainte-Marie, J., 2018. Feeding behaviour and growth of the peruvian scallop (Argopecten purpuratus) under daily cyclic hypoxia conditions. Journal of Sea Research 131, 85-94.

Avendaño, M., Le Pennec, M., 1996. Contribucion al conocimiento de la biologia reproductiva de Argopecten purpuratus (Lamarck, 1819) en Chile. Estud. Ocean. 15, 1-10.

Bellolio, G., Toledo, P., Campos, B., 1994. Morfologia de la concha larval y portlarval del ostion Argopecten purpuratus (lamarck, 1819; bivalvia, pectiniade) en chile.

Breitburg, D., Levin, L. A., Oschlies, A., Grégoire, M., Chavez, F. P., Conley, D. J., Garçon, V., Gilbert, D., Gutiérrez, D., Isensee, K., Jacinto, G. S., Limburg, K. E., Montes, I., Naqvi, S. W. A., Pitcher, G. C., Rabalais, N. N., Roman, M. R., Rose, K. A., Seibel, B. A., Telszewski, M., Yasuhara, M., Zhang, J., 2018. Declining oxygen in the global ocean and coastal waters. Science 359 (6371), 1-11.

Brown, D., Guerra, R., 1980. Recuperación gonadal en ostión Chlamys (Argopecten) purpurata (lamarck 1819) luego de evacuación de gametos. Arch. Biol. Med. Exp 13 (3), 363-368.

Bruland, K. W., Rue, E. L., Smith, G. J., DiTullio, G. R., 2005. Iron, macronutrients and diatom blooms in the Peru upwelling regime: Brown and blue waters of Peru. Mar. Chem. 93 (2-4), 81-103.

Burnett, L. E., Stickle, W. B., 2001. Physiological responses to hypoxia. In: Rabalais, N., Turner, R. (Eds.), Coast. Hypoxia Consequences Living Resour. Ecosyst. Coast. Estuar. Stud., american g Edition. Wiley Online Library, Washington D.C., pp. 101-114.

Cabello, R., Tam, J., Jacinto, M. E., 2002. Procesos naturales y antropogénicos asociados al evento de mortalidad de conchas de abanico ocurrido en la bahía de Paracas (Pisco , Peru) en junio del 200. Rev. peru. biol. 9 (2), $49-65$.

Crain, C. M., Kroeker, K., Halpern, B. S., 2008. Interactive and cumulative effects of multiple human stressors in marine systems. Ecol. Lett. 11 (12), 1304-1315.

Cueto-Vega, R., 2016. Influencia de las variables ambientales sobre el indice gonado-somatico de la concha de abanico Argopecten purpuratus (L.1819) en la Bahia de Paracas. Thesis, Facultad de Pesqueria, Universidad Nacional Agraria La Molina.

Diaz, R. J., Rosenberg, R., 1995. Marine benthic hypoxia: a review of its ecological effect and the behavioural responses of benthic macrofauna. Oceanogr. Mar. Biol. 33, 245-303.

Disalvo, L. H., Alarcon, A., Martinez, E., Uribe, E., 1984. Progress in mass culture of Chlamys (Argopecten) purpurata Lamarck (1819) with notes on its natural history. Rev. Chil. Hist. Nat. 54, 35-45.

Dupont-Prinet, A., Pillet, M., Chabot, D., Hansen, T., Tremblay, R., Audet, C., 2013a. Northern shrimp (Pandalus borealis) oxygen consumption and metabolic enzyme activities are severely constrained by hypoxia in the Estuary and Gulf of St. Lawrence. J. Exp. Mar. Bio. Ecol. 448, 298-307.

Dupont-Prinet, A., Vagner, M., Chabot, D., Audet, C., MacLatchey, D., 2013b. Impact of hypoxia on the metabolism of Greenland halibut (Reinhardtius hippoglossoides). Can. J. Fish. Aquat. Sci. 70 (3), 461-469.

Gewin, V., 2010. Dead in the water. Nature 466 (August), 812-814.

González-Hunt, R. M., 2010. Auge y crisis: la pesquería de la concha de abanico (Argopecten purpuratus) en la región PiscoParacas , costa sur del Perú. Espac. y Desarro. 22, 25-51.

Grieshaber, M. K., Hardewig, I., Kreutzer, U., Pörtner, H. O., 1994. Physiological and metabolic responses to hypoxia in invertebrates. Rev. Physiol. Biochem. Pharmacol. 125, 43-147.

Helly, J. J., Levin, L. A., 2004. Global distribution of naturally occurring marine hypoxia on continental margins. Deep Sea Res. I 
51 (9), 1159-1168.

Herreid, C. F., 1980. Review hypoxia in invertebrates. Comp. Biochem. Physiol. 67A, 311-320.

Hicks, D. W., McMahon, R. F., 2005. Effects of Temperature on Chronic Hypoxia Tolerance in the Non-Indigenous Brown Mussel, Perna Perna (Bivalvia: Mytilidae) From the Texas Gulf of Mexico. J. Molluscan Stud. 71, 401-408.

Hochachka, P. W., Buck, L. T., 1996. Unifying theory of hypoxia tolerance: Molecular/metabolic defense and rescue mechanisms for surviving oxygen lack. Proc. Natl. Acad. Sci. United States Am. Biochem. 93, 9493-9498.

Joyner-Matos, J., Downs, C. A., Julian, D., 2006. Increased expression of stress proteins in the surf clam Donax variabilis following hydrogen sulfide exposure. Comp. Biochem. Physiol. - A Mol. Integr. Physiol. 145 (2), $245-257$.

Joyner-Matos, J., Predmore, B. L., Stein, J. R., Leeuwenburgh, C., Julian, D., 2010. Hydrogen sulfide induces oxidative damage to RNA and DNA in a sulfide-tolerant marine invertebrate. Physiol. Biochem. Zool. 83 (2), 356-365.

Kooijman, S., 2013. Waste to hurry: dynamic energy budgets explain the need of wasting to fully exploit blooming resources. Oikos $122(3), 348-357$.

Kooijman, S. A. L. M., 2010. Dynamic Energy Budget theory for metabolic organisation - third edition, cambridge Edition. Cambridge University Press.

Kramer, D. L., 1987. Dissolved oxygen and fish behavior. Environ. Biol. Fishes 18 (2), 81-92.

Laudien, J., Schiedek, D., Brey, T., Po, H., 2002. Survivorship of juvenile surf clams Donax serra (Bivalvia , Donacidae) exposed to severe hypoxia and hydrogen sulphide. J. Exp. Mar. Bio. Ecol. 271, 9-23.

Lavaud, R., Flye-Sainte-Marie, J., Jean, F., Emmery, A., Strand, O., Kooijman, S. A. L. M., 2014. Feeding and energetics of the great scallop, Pecten maximus, through a deb model. Journal of Sea Research 94 (0), 5-18.

Lavaud, R., Thomas, Y., Pecquerie, L., Benoit, H., Swain, D., Guyondet, T., Flye-Sainte-Marie, J., Chabot, D., 2018. Modelling the impact of hypoxia on the energy budget of Atlantic cod in two populations in the Gulf of Saint-Lawrence. Journal of Sea Research , this issue.

Levin, L., Ekau, W., a.J. Gooday, Jorissen, F., Middelburg, J., Naqvi, S., Neira, C., Rabalais, N., Zhang, J., 2009. Effects of natural and human-induced hypoxia on coastal benthos. Biogeosciences (6), 2063-2098.

Levin, L. A., 2003. Oxygen minimum zone benthos: adaptation and community reponse to hypoxia. Oceanogr. Mar. Biol. 41, $1-45$.

Marques, G. M., Augustine, S., Lika, K., Pecquerie, L., Domingos, T., Kooijman, S. A. L. M., 2018. The AmP project: Comparing species on the basis of dynamic energy budget parameters. PLOS Computational Biology 14 (5), e1006100.

Mendo, J., Yamashiro, C., Rubio, J., Kameya, A., Maldonado, M., Guzman, S., 1989. Evaluation de la poblacion de concha de abanico (Argopecten purpuratus) en la bahia de Independencia, Pisco, Peru. 23 de Setiembre - 9 de Octubre de 1987. Tech. rep., IMARPE, Callao.

Montalto, V., Sarà, G., Ruti, P., 2014. Testing the effects of temporal data resolution on predictions of the effects of climate change on bivalves. Ecol. Modell. 278, 1-8.

Muller, E. B., Nisbet, R. M., Berkley, H. A., 2010. Sublethal toxicant effects with dynamic energy budget theory: Model formulation. Ecotoxicology 19 (1), 48-60.

Nisbet, R. M., Jusup, M., Klanjscek, T., Pecquerie, L., 2012. Integrating dynamic energy budget (DEB) theory with traditional bioenergetic models. J. Exp. Biol. 215 (6), 892-902.

Rabalais, N. N., Díaz, R. J., Levin, L. a., Turner, R. E., Gilbert, D., Zhang, J., 2010. Dynamics and distribution of natural and 
human-caused hypoxia. Biogeosciences 7 (2), 585-619.

Rojas de Mendiola, B., 1981. Seasonal phytoplankton distribution along the Peruvian coast. Coast. Estuar. Sci. 1, $348-356$.

Schunck, H., Lavik, G., Desai, D. K., Grosskopf, T., Kalvelage, T., Loscher, C. R., Paulmier, a., Contreras, S., Siegel, H., Holtappels, M., Rosenstiel, P., Schilhabel, M. B., Graco, M., Schmitz, R. a., Kuypers, M. M., Laroche, J., 2013. Giant Hydrogen Sulfide Plume in the Oxygen Minimum Zone off Peru Supports Chemolithoautotrophy. PLoS One 8 (8), e68661.

Sousa, T., Domingos, T., Poggiale, J.-C., Kooijman, S. A. L. M., 2010. Dynamic energy budget theory restores coherence in biology. Philosophical Transactions of the Royal Society of London B: Biological Sciences 365 (1557), 3413-3428.

Stotz, W., Gonzalez, S., 1997. Abundance, growth, and production of the sea scallop argopecten purpuratus ( lamarck 1819): bases for sustainable exploitation ef natural scallop beds in north-central chile. Fish. Res. 32, 173-183.

Thomas, Y., Flye-Sainte-Marie, J., Chabot, D., Aguirre-Velarde, A., L., P., 2018. Effects of hypoxia on metabolic functions in marine organisms: observed patterns and modelling assumptions within the context of Dynamic Energy Budget (DEB) theory. J. Sea Res. , this issue.

Thomas, Y., Mazurié, J., Alunno-Bruscia, M., Bacher, C., Bouget, J. F., Gohin, F., Pouvreau, S., Struski, C., 2011. Modelling spatio-temporal variability of Mytilus edulis (L.) growth by forcing a dynamic energy budget model with satellite-derived environmental data. J. Sea Res. 66 (4), 308-317.

Wang, W., Widdows, J., 1993. Calorimetric studies on the energy metabolism of an infaunal bivalve, abra tenuis, under normoxia, hypoxia and anoxia. Marine Biology 116 (1), 73-79.

Willows, R. I., 1992. Optimal digestive investment: A model for filter feeders experiencing variable diets. Limnol. Oceanogr. 37 (4), 829-847.

Wolff, M., 1987. Population dynamics of the peruvian scallop Argopecten purpuratus during the El Niño phenomenon of 1983. Can. J. Fish. Aquat. Sci. 44, 1684-1691.

Wolff, M., 1988. Spawning and recruitment in the Peruvian scallop Argopecten purpuratus. Mar. Ecol. Prog. Ser. $42,213-217$.

Wu, R. S. S., 2002. Hypoxia: from molecular responses to ecosystem responses. Mar. Pollut. Bull. 45, 35-45. 

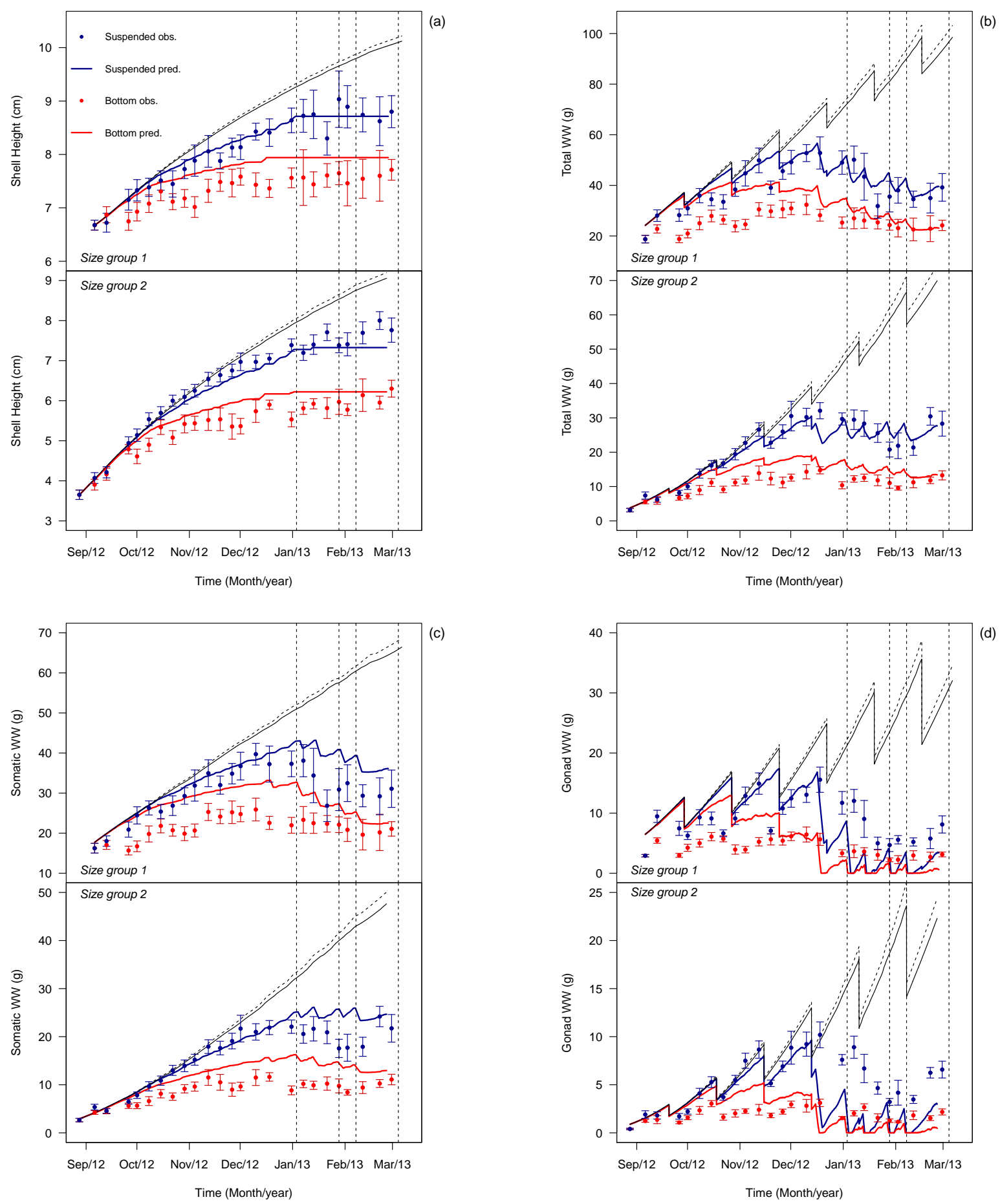

Figure 5: Simulations (lines) of shell height (a), total wet weight (WW) (b), somatic wet weight (c) and gonad wet weight (d) for the two size groups (initial shell height of 3.65 and $6.68 \mathrm{~cm}$ for group 2 and 1, respectively) of $A$. purpuratus scallops cultivated on the bottom and in suspended cages in Paracas Bay between August 2012 and March 2013. Points represent observed means and bars the 95\% confidence intervals. Dotted vertical lines correspond to the different milky water events observed in Paracas Bay. Black lines correspond to simulations performed without the effect of hypoxia and milky waters. Continuous black line: bottom, dashed black line: suspended. 